\title{
Numerical Analysis of Heat and Mass Transfer Flow of Nanofluid over a Moving Wedge Using Spectral Quasilinearization Method
}

\author{
Ayele Tulu ${ }^{1,}$, Wubshet Ibrahim ${ }^{2}$ \\ ${ }^{1}$ Department of Mathematics, Wollega University, Nekemte, Ethiopia \\ ${ }^{2}$ Departments of Mathematics, Ambo University, Ambo, Ethiopia
}

Email address:

ayeletulu@gmail.com (A. Tulu)

${ }^{*}$ Corresponding author

\section{To cite this article:}

Ayele Tulu, Wubshet Ibrahim. Numerical Analysis of Heat and Mass Transfer Flow of Nanofluid over a Moving Wedge Using Spectral Quasilinearization Method. International Journal of Applied Mathematics and Theoretical Physics. Vol. 5, No. 4, 2019, pp. 111-117. doi: 10.11648/j.ijamtp.20190504.13

Received: September 7, 2019; Accepted: October 28, 2019; Published: December 10, 2019

\begin{abstract}
In this paper the problem of unsteady two-dimensional heat and mass transfer flow of nanofluid past a moving wedge is considered. The effects of nanoparticle volume fraction, viscous dissipation, chemical reaction, and convective boundary conditions are studied. The physical problem is modeled using partial differential equations. Using suitable similarity variables, the governing equations and their related boundary conditions are transformed into dimensionless forms of a system of coupled nonlinear ordinary differential equations. The resulting systems of equations are then solved numerically using spectral quasilinearization method (SQLM). The results reveal that the skin friction coefficient increases with increasing the values of nanoparticle volume fraction, unsteadiness and permeability parameters. The local Nusselt number reduces with increasing the value of nanoparticle volume fraction, Prandtl number and Eckert number. The local Sherwood number enhances with greater the value of nanoparticle volume fraction, unsteadiness, pressure gradient and chemical reaction parameters. Moreover, the method is checked against the previously published results and a very good agreement have been obtained.
\end{abstract}

Keywords: Unsteady Flow, Wedge Surface, Nanofluid, Viscous Dissipation, Spectral Quasilinearization Method

\section{Introduction}

In the past few years, researchers have continuously worked on developing innovative heat transfer fluids that have significantly higher thermal conductivities than usually used fluids. In 1995, Choi was the first scholar who developed a newly pioneering type of heat transfer fluids, and he gave the term "nanofluids" for such type of fluids. He prepared these fluids on sagging nanoscale particles of metallic basis with particle size less than $100 \mathrm{~nm}$ into conventional heat transfer fluids. Choi noticed that the addition of 1 volume percent of nanoparticles to the usual fluids increases the thermal conductivity of the fluid approximately twice [1]. Nanofluids have been receiving great attention in recent years not only due to their greater in thermal conductivity but also potentially useful in many modern-day applications. Some of these include microelectronics, fuel cells, food processing, biomedicine, power generation, ventilation, engine vehicle management, domestic refrigerator, and heat exchanger [2]. Some recent studies on boundary layer flow of nanofluid include the work of these scholars [3-5].

Fluid flows with heat and mass transfer over a wedge shaped bodies is happened in many thermal engineering applications such as heat exchangers, crude oil extraction, thermal insulation, geothermal systems and the storage of nuclear waste [6-7]. In recent times, boundary layer flow of heat and mass transfer of nanofluids over a wedge has become a current topic of interest. Srinivasacharya et al. [8] analyzed MHD flow in a nanofluid over a wedge, and they found that an increment in the pressure gradient parameter reduces the rate of heat and mass transfer. The boundary 
layer flow of $\mathrm{Cu}$-Water and Ag-Water nanofluids pass through a permeable wedge was investigated by $\mathrm{Xu}$ and Chen [9]. They concluded that the occurrence of flow separation has several undesirable effects, and it leads to an increase in the drag force on a body immersed in a flow.

Viscous dissipation is the heat energy that is produced as a result of friction between fluid layers. It changes the temperature distribution by playing a role like an energy source that leads to affect heat transfer rate. Haile and Shankar [10] analyzed heat and mass transfer of MHD flow of nanofluids in the presence of viscous dissipation effects. They noticed that viscous dissipation parameter enhances the temperature profiles while it reduces concentration profiles. Mass convection is the mass transfer mechanism between a surface and a moving fluid that involves both mass diffusion and bulk fluid motion [11]. The flow of fluid is affected by chemical reactions that take place in it. Majety and Gangadhar [12] considered MHD boundary layer flow of nanofluids past a wedge with viscous dissipation and chemical reaction effects. They concluded that the mass transfer rate at the boundary surface increases with increasing Lewis number and chemical reaction parameter.

The study of unsteady heat and mass transfer flow of nanofluid over a moving wedge has been not given much consideration so far. The aim of the present study is to analyze the effect of nanoparticle volume friction and the effects of various physical parameters on heat and mass transfer flow of nanofluid over a moving wedge with convective boundary condition. For this study we considered $\mathrm{Cu}-\mathrm{H}_{2} \mathrm{O}$ nanofluid, and the model equations are numerically solved using SQLM. Employing SQLM are advantageous due to its fast convergence, easy to implement, adaptable to various problems, provide more accurate approximations with a relatively small number of unknowns, and require less grid points to achieve accurate results as shown in the study [13-14]. Further, the effects of different parameters on heat and mass transfer flow of nanofluid are analyzed with the help of tables and graphical representations.

\section{Mathematical Problem Description}

We considered unsteady two-dimensional laminal boundary layer flow of nanofluid past a moving wedge. It is assumed that the coordinate system is chosen with $x$ corresponding to the plane in the course of the flow and $y$ indicating towards the free stream as shown in Figure 1 below. Further, it is assumed that the wedge is maintained respectively with variable wall temperature and nanoparticle concentration $\quad T_{w}(x, t)=T_{\infty}+T_{0}(x / 1-\gamma t)^{2 m} \quad$ and $C_{w}(x, t)=C_{\infty}+C_{0}(x / 1-\gamma t)^{2 m}$, where $T_{0}$ and $C_{0}$ are positive constants reference temperature and concentration. $T_{w}$ and $C_{w}$ are respectively greater than the ambient temperature $T_{\infty}$ and ambient nanoparticle concentration $C_{\infty}$, and $\gamma \geq 0$ is constant with dimension reciprocal time, $t$ is time and $\gamma t<1$. It is also assumed that the nanofluid fluid have constant physical properties.

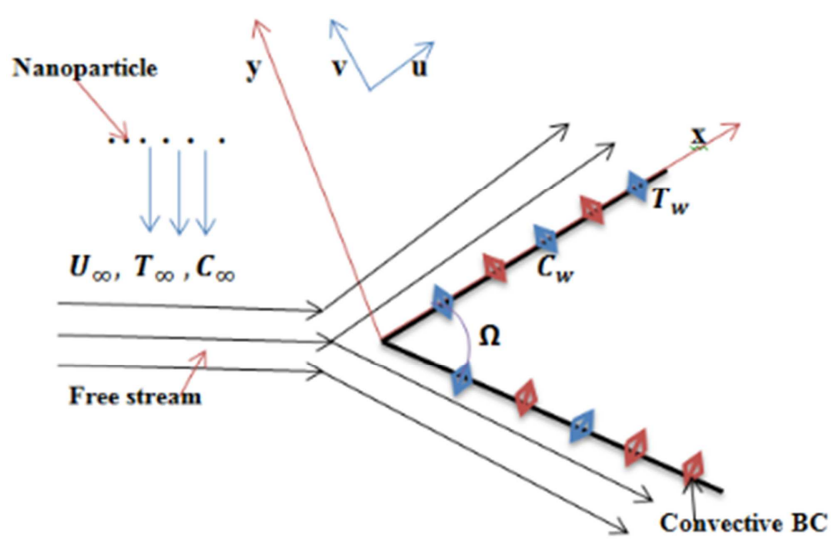

Figure 1. Physical model of flow configuration.

Using the above assumptions and the boundary layer approximations the continuity, momentum, energy, and concentration equations governing the considered problem are given as:

$$
\begin{gathered}
\frac{\partial u}{\partial x}+\frac{\partial v}{\partial y}=0 \\
\frac{\partial u}{\partial t}+u \frac{\partial u}{\partial x}+v \frac{\partial u}{\partial y}=-\frac{1}{\rho_{n f}} \frac{\partial p}{\partial x}+v_{n f} \frac{\partial^{2} u}{\partial y^{2}} \\
\frac{\partial T}{\partial t}+u \frac{\partial T}{\partial x}+v \frac{\partial T}{\partial y}=\alpha_{n f} \frac{\partial^{2} T}{\partial y^{2}}+\frac{v_{n f}}{\left(c_{p}\right)_{n f}}\left(\frac{\partial u}{\partial y}\right)^{2} \\
\frac{\partial C}{\partial t}+u \frac{\partial C}{\partial x}+v \frac{\partial C}{\partial y}=D_{B} \frac{\partial^{2} C}{\partial y^{2}}-k_{r}\left(C-C_{\infty}\right)
\end{gathered}
$$

The appropriate convective boundary conditions are given as:

$$
\begin{gathered}
\mathrm{t}<0 ; u=0 ; v=0 ; T=T_{\infty} ; C=C_{\infty} \forall_{x, y} \\
\mathrm{t} \geq 0 ; u=u_{w}(x, t)=\frac{u_{0}}{1-\gamma t} x^{m} ; v=0 ; \\
k_{f} \frac{\partial T}{\partial y}=-h_{f}\left(T_{w}-T\right) ; D_{m} \frac{\partial C}{\partial y}=-h_{s}\left(C_{w}-C\right) \text { at } y=0 \\
u \rightarrow U(x, t)=\frac{u_{\infty}}{1-\gamma t} x^{m} ; T \rightarrow T_{\infty} ; C \rightarrow C_{\infty} \text { as } y \rightarrow \infty
\end{gathered}
$$

where $u$ and $v$ are the $x$ and $y$ velocity components, $m, D_{B}$, $D_{m}$, and $k_{r}$ are respectively the Falkner-Skan power-law parameter, Brownian diffusion coefficient, mass diffusivity of the concentration, and rate of chemical reaction respectively. Furthermore, $h_{f}(x, t)=h_{0} x^{\frac{m-1}{2}}(1-\gamma t)^{-1 / 2}$ and $h_{s}(x, t)=h_{1} x^{\frac{m-1}{2}}(1-\gamma t)^{-1 / 2}$ are convective heat and mass transfer coefficients respectively, where $h_{0}$ and $h_{1}$ being constants. The expression $T_{w}, C_{w}, u_{w}, h_{f}$, and $h_{s}$ are valid for $t>\gamma^{-1}$. The nanofluid effective density $\rho_{n f}$, kinematic viscosity $v_{n f}$, thermal diffusivity $\alpha_{n f}$, specific heat capacity $\left(c_{p}\right)_{n f}$, and thermal conductivity $k_{n f}$ are determined using nanoparticle and base fluid thermophysical properties as follows [15].

$$
\rho_{n f}=\delta \rho_{s}+(1-\delta) \rho_{f} ; \quad\left(c_{p}\right)_{n f}=\delta\left(\rho c_{p}\right)_{s}+(1-\delta)\left(\rho c_{p}\right)_{f}
$$




$$
\mu_{n f}=\frac{\mu_{f}}{(1-\delta)^{2.5}} ; v_{n f}=\frac{v_{f}}{\delta_{1}} ; \alpha_{n f}=\frac{k_{n f}}{\delta_{2}\left(\rho c_{p}\right)_{f}}
$$

where $\delta$ is the nanoparticle volume fraction, and the nanoparticle volume fraction $\delta_{1}$ and $\delta_{2}$ are defined as:

$$
\delta_{1}=(1-\delta)^{2.5}\left[1-\delta+\delta \frac{\rho_{s}}{\rho_{f}}\right] ; \delta_{2}=1-\delta+\delta \frac{\left(\rho c_{p}\right)_{s}}{\left(\rho c_{p}\right)_{f}}(7)
$$

The effective thermal conductivity $k_{n f}$ of nanofluids when the added particles are of spherical shape, low volume percent, and the suspension is at ambient conditions is defined using the thermal conductivities of both nanoparticles $k_{s}$ and basefluid $k_{f}$ [15].

$$
k_{n f}=k_{f} \frac{\left(k_{s}+2 k_{f}\right)-2 \delta\left(k_{f}-k_{s}\right)}{\left(k_{s}+2 k_{f}\right)+\delta\left(k_{f}-k_{S}\right)}
$$

the wedge outside the boundary layer, where $u_{\infty}$ is the free stream velocity. For a uniform stream, the pressure term in the momentum equation (2) becomes $[6,7,16]$.

$$
-\frac{1}{\rho} \frac{\partial p}{\partial x}=\frac{\partial U}{\partial t}+U \frac{d U}{d x}
$$

where, $x$ is measured from the tip of the wedge, and $m$ is the Falkner-Skan power-law parameter.

\section{Numerical Method of Solution}

To transform highly non-linear and parabolic PDEs into a system of ODEs, we introduce the stream function $\psi(x, y)$ such that $u=\frac{\partial \psi}{\partial y}, v=-\frac{\partial \psi}{\partial x}$, and the following transformation variables [17].

We assume that $U(x, t)=\frac{u_{\infty}}{1-\gamma t} x^{m}$ is the fluid velocity at

$$
\begin{gathered}
\eta=y \sqrt{\frac{1+m}{2} \frac{u_{\infty}}{v_{f}(1-\gamma t)}} x^{\frac{m-1}{2}} ; \quad \psi(x, \eta)=y \sqrt{\frac{2}{1+m} \frac{v_{f} u_{\infty}}{(1-\gamma t)}} x^{\frac{m+1}{2}} f(\eta) \\
\theta(\eta)=\frac{T-T_{\infty}}{T_{w}-T_{\infty}} ; \quad \phi(\eta)=\frac{C-C_{\infty}}{C_{w}-C_{\infty}}
\end{gathered}
$$

Here, continuity equation (1) is satisfied, and equations (2)-(4) are transformed into a dimensionless system of non-linear ODEs.

$$
\begin{gathered}
f^{\prime \prime \prime}+\delta_{1}\left[f f^{\prime \prime}+\beta\left(1-\left(f^{\prime}\right)^{2}\right)+\frac{A}{1+m}\left(2-\eta f^{\prime \prime}-2 f^{\prime}\right)\right]=0 \\
\frac{1}{P r} \frac{k_{n f}}{k_{f}} \theta^{\prime \prime}+\delta_{2}\left[f \theta^{\prime}-2 \beta f^{\prime} \theta-A\left(\frac{\eta}{1+m} \theta^{\prime}+2 \beta \theta\right)\right]+\frac{E c}{(1-\delta)^{2.5}}\left(f^{\prime \prime}\right)^{2}=0 \\
\frac{1}{S c} \phi^{\prime \prime}+f \phi^{\prime}-2 \beta f^{\prime} \phi-A\left(\frac{\eta}{1+m} \phi^{\prime}+2 \beta \phi\right)-\frac{2}{1+m} K \phi=0
\end{gathered}
$$

The transformed boundary conditions are:

$$
\begin{gathered}
f(0)=0 ; f^{\prime}(0)=\lambda ; \theta^{\prime}(0)=-B i_{1}(1-\theta(0)) ; \phi^{\prime}(0)=-B i_{2}(1-\phi(0)) \\
f^{\prime}(\infty) \rightarrow 1 ; \theta(\infty) \rightarrow 0 ; \phi(\infty) \rightarrow 0
\end{gathered}
$$

with

$$
\begin{gathered}
A=\frac{\gamma}{u_{\infty}} x^{1-m} ; \beta=\frac{2 m}{1+m} ; E c=\frac{U^{2}}{\left(c_{p}\right)_{f}\left(T_{w}-T_{\infty}\right)} ; \operatorname{Pr}=\frac{v_{f}}{\alpha_{f}} ; S c=\frac{v_{f}}{D_{B}} \\
K=\frac{k_{r}}{U} x^{-1} ; \lambda=\frac{u_{0}}{u_{\infty}} ; R e_{x}=\frac{u_{w}}{v_{f}} x ; B i_{1}=\frac{h_{0}}{k_{f}}\left(\frac{2 v_{f}}{(1+m) u_{\infty}}\right)^{\frac{1}{2}} ; B i_{2}=\frac{h_{1}}{D_{B}}\left(\frac{2 v_{f}}{(1+m) u_{\infty}}\right)^{\frac{1}{2}}
\end{gathered}
$$

where $A, \beta, E c, P r, S c, K, \lambda, R e_{x}, B i_{1}$ and $B i_{2}$ are respectively unsteadiness parameter, Hartree pressure gradient parameter, Eckert number, Prandtl number, Schmidt number, chemical reaction parameter, moving wedge parameter, local Reynolds number, and Biot numbers.

The physical quantities of engineering interest in the present study are the skin friction coefficient $C_{f}$, local Nusselt number $N u_{x}$ and local Sherwood number $S h_{x}$, and their nondimensional forms are respectively defined as

$$
\begin{gathered}
\frac{1}{2}(1-\delta)^{2.5} \sqrt{\frac{2}{1+m}} C_{f} \sqrt{R e_{x}}=-f^{\prime \prime}(0), \\
\frac{k_{f}}{k_{n f}} \sqrt{\frac{2}{1+m}} \frac{N u_{x}}{\sqrt{R e_{x}}}=-\theta^{\prime}(0), \sqrt{\frac{2}{1+m}} \frac{S h_{x}}{\sqrt{R e_{x}}}=-\phi^{\prime}(0)
\end{gathered}
$$

The systems of non-linear ODE have been solved numerically using SQLM. The main idea behind this approach is identifying univariate and multivariate nonlinear 
terms of function and its derivative in each of the equations of the system, linearizing the terms and applying Chebyshev pseudo-spectral collocation method (for details see [7, 13]).
For this study, $\mathrm{Cu}$ as nanoparticle and $\mathrm{H}_{2} \mathrm{O}$ as base fluid are considered and their thermophysical properties are given in Table 1.

Table 1. Thermophysical properties of base fluid $\left(\mathrm{H}_{2} \mathrm{O}\right)$ and nanoparticles $(\mathrm{Cu})[3,17]$.

\begin{tabular}{|c|c|c|c|c|c|}
\hline Physical Properties & $c_{p}(J / k g K)$ & $\rho\left(k g / m^{3}\right)$ & $\boldsymbol{k}(\boldsymbol{W} / \boldsymbol{m} \boldsymbol{K})$ & $\alpha \times 10^{7}\left(m^{2} / s\right)$ & $\beta \times 10^{5}\left(K^{-1}\right)$ \\
\hline Water $\left(\mathrm{H}_{2} \mathrm{O}\right)$ & 4179 & 997.1 & 0.613 & 1.47 & 21 \\
\hline Copper $(\mathrm{Cu})$ & 385 & 8933 & 401 & 1163.1 & 1.67 \\
\hline
\end{tabular}

\section{Results and Discussions}

Convergence of SQLM solutions are achieved at few orders of approximations. Presented values in Table 2 tested the $4^{\text {th }}$ order of approximations for skin friction coefficient $-f^{\prime \prime}(0)$ and local Nusselt number $-\theta^{\prime}(0)$, and $3^{\text {rd }}$ order of approximations for local Sherwood number $-\phi^{\prime}(0)$ are enough. Unless it is specified the parameters value used for this study are $\beta=0.5, \delta=0.1, \operatorname{Pr}=6.2, S c=1, \quad A=$ $0.8, E c=0.5, \lambda=0, K=0.3, B i_{1}=B i_{2}=0.5$.

Table 2. SQLM Solutions Convergence when values of the above parameters used.

\begin{tabular}{llll}
\hline Order of iteration & $-\boldsymbol{f}^{\prime \prime}(\mathbf{0})$ & $-\boldsymbol{\theta}^{\prime}(\mathbf{0})$ & $-\boldsymbol{\phi}^{\prime}(\mathbf{0})$ \\
\hline 01 & 1.81534698 & 0.26835422 & 0.99696643 \\
02 & 1.79905319 & 0.22883592 & 1.03499689 \\
03 & 1.79901484 & 0.22881896 & 1.03505129 \\
04 & 1.79901484 & 0.22881896 & 1.03505129 \\
05 & 1.79901484 & 0.22881896 & 1.03505129 \\
\hline
\end{tabular}

To confirm the numerical accuracy of the numerical method used, for different values of $\mathrm{m}$ the skin friction coefficient $-f^{\prime \prime}(0)$ and local Nusselt number $-\theta(0)$ are compared with previously published results [7, 18, 19] keeping the rest parameters value remain constant. Here, Table 3 shows that a very good agreement is realized which in turn confirm the accuracy of the present solutions.

Table 3. Comparison of the SQLM results of skin friction coefficient $-f^{\prime \prime}(0)$ and local Nusselt number $-\theta^{\prime}(0)$ for various values of $m$ for Pr $=0.73, S c=$ $1, A=E c=\lambda=K=0, B i_{1}=B i_{2}=\infty$.

\begin{tabular}{|c|c|c|c|c|c|c|c|}
\hline \multirow{2}{*}{ m } & \multirow{2}{*}{ Ibrahim [7] } & \multicolumn{3}{|l|}{$-\boldsymbol{f}^{\prime \prime}(\mathbf{0})$} & \multicolumn{3}{|l|}{$-\boldsymbol{\theta}^{\prime}(\mathbf{0})$} \\
\hline & & Ashwini [18] & Watanaba [19] & Present & Ibrahim [7] & Watanaba [19] & Present \\
\hline 0.0000 & 0.46960 & 0.4696 & 0.46960 & 0.46960 & 0.42016 & 0.42015 & 0.42016 \\
\hline 0.0141 & 0.50461 & 0.5046 & 0.50461 & 0.50461 & 0.42578 & 0.42578 & 0.42578 \\
\hline 0.0435 & 0.56898 & 0.5690 & 0.56898 & 0.56898 & 0.43548 & 0.43548 & 0.43548 \\
\hline 0.0909 & 0.65498 & 0.6550 & 0.65498 & 0.65498 & 0.44730 & 0.44730 & 0.44730 \\
\hline 0.1429 & 0.73200 & 0.7320 & 0.73200 & 0.73200 & 0.45694 & 0.45693 & 0.45694 \\
\hline 0.2000 & 0.80213 & 0.8021 & 0.80213 & 0.80213 & 0.46503 & 0.46503 & 0.46503 \\
\hline 0.5000 & 1.03907 & - & 1.03890 & 1.03907 & - & - & - \\
\hline 1.0000 & 1.23258 & 1.2326 & - & 1.23258 & - & - & - \\
\hline
\end{tabular}

Table 4 shows that the skin friction coefficient is an increasing function of nanoparticle volume fraction, unsteadiness, and pressure gradient parameters. The local Nusselt number is a decreasing function of nanoparticle volume fraction parameter, Prandtl number, and Eckert number while it is an increasing function of unsteadiness and pressure gradient parameters. Sherwood number is increased by increasing the value of nanoparticle volume fraction, unsteadiness, pressure gradient, chemical reaction parameters, and Schmidt number. Similar results can be found in the literatures $[3,7]$.

Table 4. Computations of the skin friction coefficient $-f^{\prime \prime}(0)$, local Nusselt number $-\theta^{\prime}(0)$ and local Sherwood number $-\phi^{\prime}(0)$ for Cu $-\mathrm{H}_{2} \mathrm{O}$ nanofluid for various parameters with $\lambda=0, B i_{1}=B i_{2}=0.5$.

\begin{tabular}{|c|c|c|c|c|c|c|c|c|c|}
\hline $\bar{\delta}$ & $\boldsymbol{A}$ & $\beta$ & $P r$ & $E c$ & $S c$ & $K$ & $-\boldsymbol{f}^{\prime \prime}(\mathbf{0})$ & $-\boldsymbol{\theta}^{\prime}(\mathbf{0})$ & $-\phi^{\prime}(0)$ \\
\hline 0.0 & 0.8 & 0.5 & 6.2 & 0.5 & 1.0 & 0.3 & 1.43112346 & 0.77276091 & 1.00140529 \\
\hline 0.1 & & & & & & & 1.68120660 & 0.23100022 & 1.01664711 \\
\hline 0.2 & & & & & & & 1.74317108 & -0.04716890 & 1.02013327 \\
\hline \multirow{8}{*}{0.1} & 0.8 & & & & & & 1.68120660 & 0.23100022 & 1.01664711 \\
\hline & 1.2 & & & & & & 1.91065992 & 0.31518191 & 1.12379038 \\
\hline & 0.8 & 0.0 & & & & & 1.56834451 & -0.91189087 & 0.69753429 \\
\hline & & 0.5 & & & & & 1.68120660 & 0.23100022 & 1.01664711 \\
\hline & & 0.5 & 1.0 & & & & 1.68120660 & 0.44250967 & 1.01664711 \\
\hline & & & 5.0 & & & & 1.68120660 & 0.31015300 & 1.01664711 \\
\hline & & & 10 & & & & 1.68120660 & -0.03885493 & 1.01664711 \\
\hline & & & 6.2 & 0.2 & & & 1.68120660 & 1.09092522 & 1.01664711 \\
\hline
\end{tabular}




\begin{tabular}{|c|c|c|c|c|c|c|c|c|c|}
\hline$\delta$ & $A$ & $\beta$ & $\mathrm{Pr}$ & $E \boldsymbol{E}$ & $S c$ & $K$ & $-f^{\prime \prime}(0)$ & $-\theta^{\prime}(0)$ & $-\phi^{\prime}(0)$ \\
\hline & & & & 0.5 & & & 1.68120660 & 0.23100022 & 1.01664711 \\
\hline & & & & 1.0 & & & 1.68120660 & -0.20220812 & 1.01664711 \\
\hline & & & & 0.5 & 0.2 & & 1.68120660 & 0.23100022 & 0.48992546 \\
\hline & & & & & 0.5 & & 1.68120660 & 0.23100022 & 0.74287976 \\
\hline & & & & & 1.0 & & 1.68120660 & 0.23100022 & 1.01664711 \\
\hline & & & & & 0.5 & 0.2 & 1.68120660 & 0.23100022 & 0.97818737 \\
\hline & & & & & & 0.5 & 1.68120660 & 0.23100022 & 1.09021018 \\
\hline & & & & & & 0.8 & 1.68120660 & 0.23100022 & 1.19336693 \\
\hline
\end{tabular}

Figures 2 and 3 respectively show that increasing nanoparticle volume fraction leads to the increment of the fluid velocity and temperature profiles. It is also noticed that the thermal boundary layer thickness increases while the velocity boundary layer thickness decrease. Figures 4, 5 and 6 illustrated that increasing the unsteadiness parameter increases the velocity profiles while it reduces the temperature and concentration profiles respectively. The thickness of the momentum boundary layer, thermal boundary layer, and concentration boundary layer reduce with the increasing value of unsteadiness parameter.

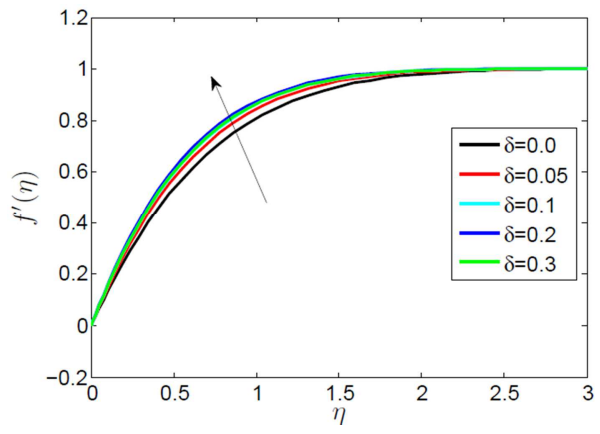

Figure 2. Velocity profiles for various values of $\delta$.

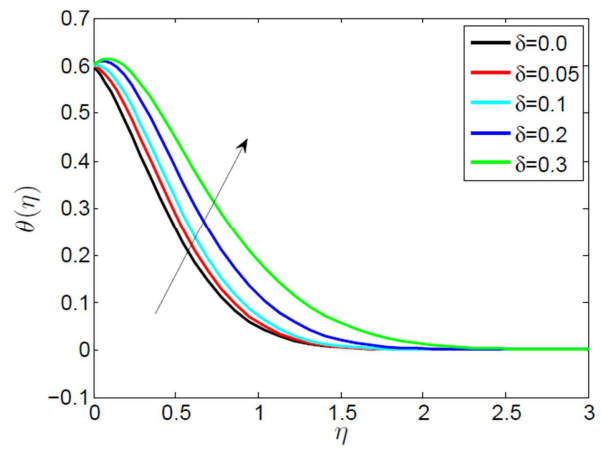

Figure 3. Temperature profiles for various values of $\delta$.

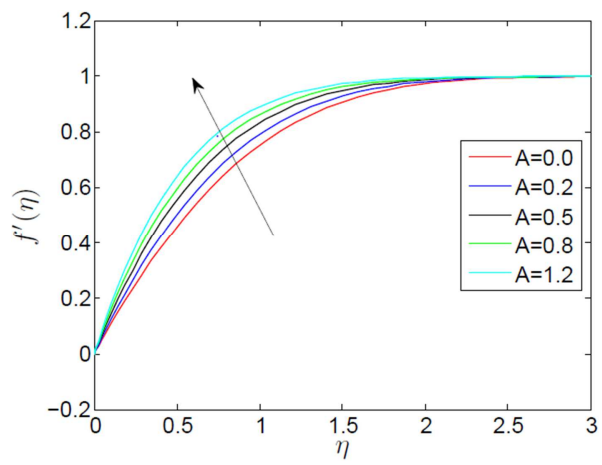

Figure 4. Velocity profiles for various values of $A$.

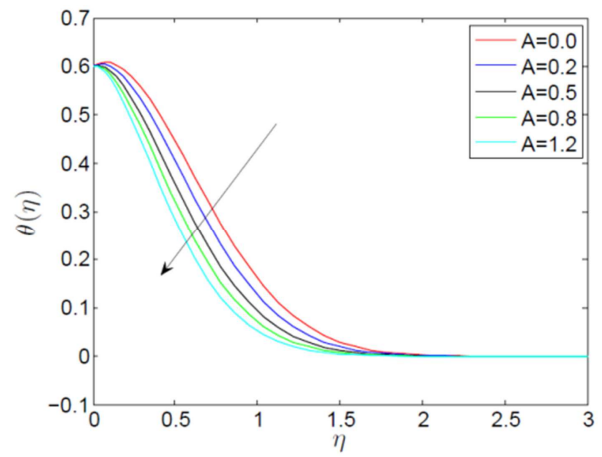

Figure 5. Temperature profiles for various values of $A$.

Figure 7 demonstrates that the velocity profile increases with an increase in pressure gradient parameter. This is because of the increment of wedge angle, the fluid moves much slower and decreases velocity boundary layer thickness. Figures 8 and 9 also display that increasing the pressure gradient parameter leads to reduce the temperature and concentration profiles as well as their boundary layer thickness.

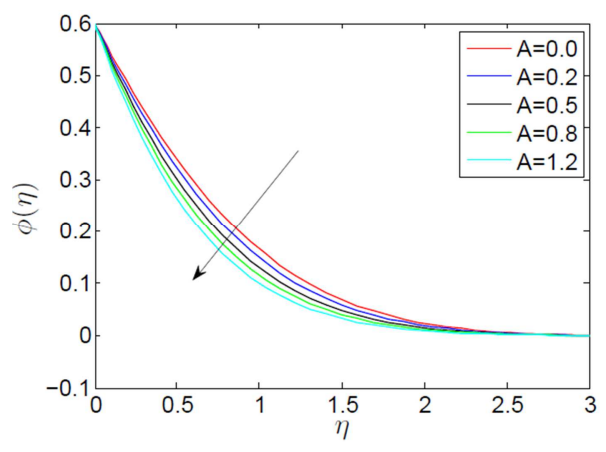

Figure 6. Concentration profiles for various values of $A$.

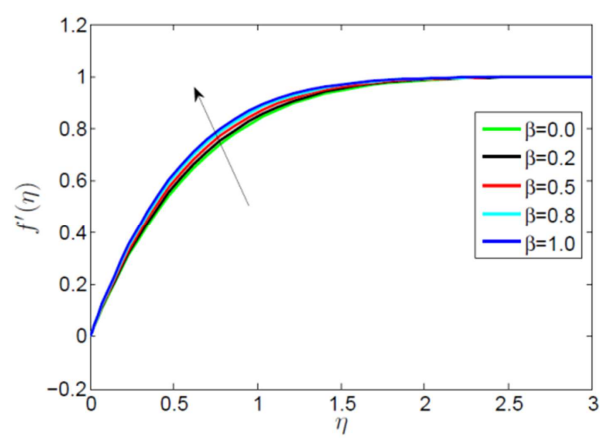

Figure 7. Velocity profiles for various values of $\beta$.

The Eckert number expresses the conversion of kinetic energy into internal energy by work done against the viscous fluid stress. Figure 10 shows that temperature increases 
significantly from the surface and attains a peak value around $\eta=0.5$, and then decreases in the rest of the region. Figure 11 reveals that the concentration profiles and its boundary layer thickness reduce with increment of the chemical reaction parameters. Similar trends are pointed out in [3].

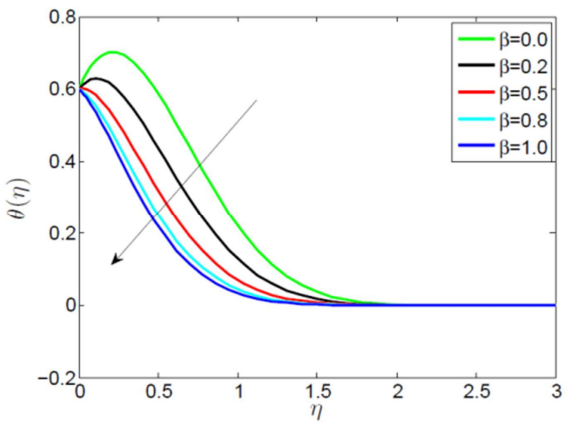

Figure 8. Temperature profiles for various values of $\beta$.

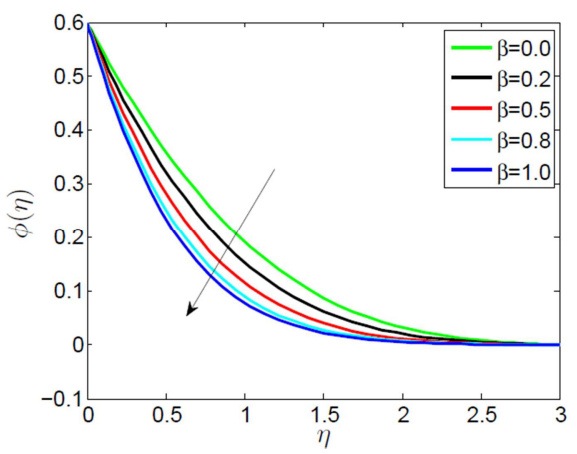

Figure 9. Concentration profiles for various values of $\beta$.

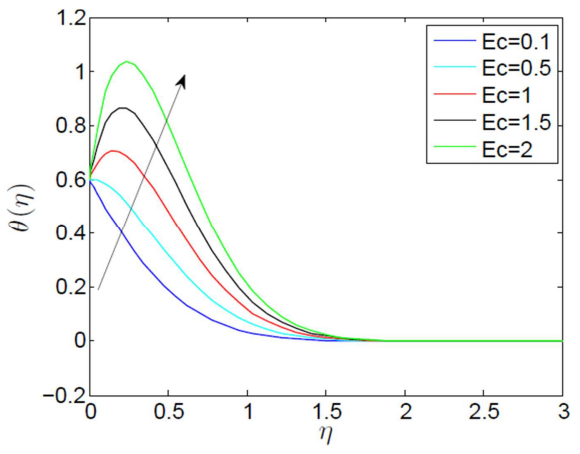

Figure 10. Temperature profiles for various values of Ec.

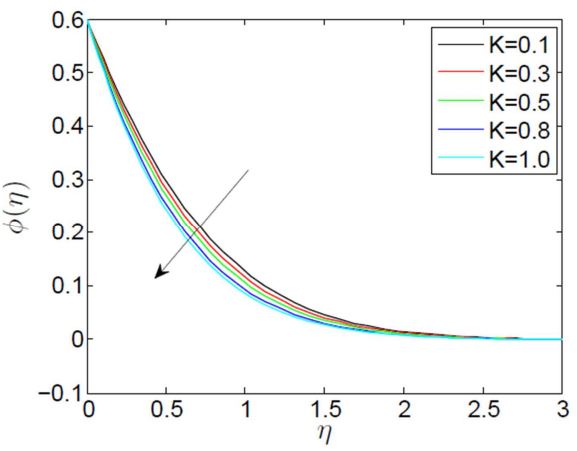

Figure 11. Concentration profiles for various values of $K$.

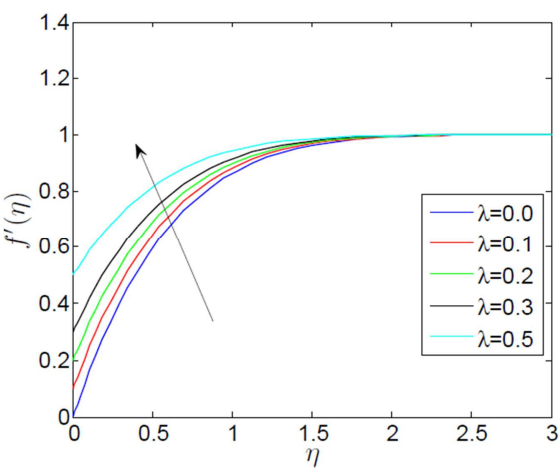

Figure 12. Velocity profiles for various values of $\lambda$.

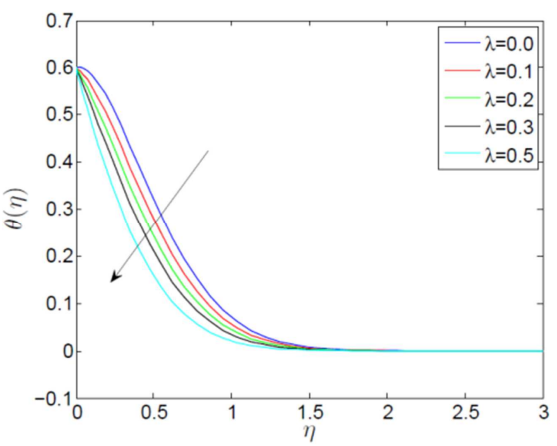

Figure 13. Temperature profiles for various values of $\lambda$

Figures 12 and 13 show the effect of the moving wedge parameter $\lambda$ on velocity and temperature profiles. Figure 12 displays that the velocity profiles is increasing function of the moving wedge parameter. This implies that when wedge moves (for non-zero values of $\lambda$ ) the fluid velocity at the surface of the wedge is no longer equal to the initial fluid velocity. Increasing $\lambda$ enhances the velocity profiles while it decreases the velocity boundary layer thickness. Figure 13 also reveals that as $\lambda$ increases the temperature and its boundary layer thickness decrease.

Figure 14 shows that the increment of $\mathrm{Bi}_{1}$ leads to increase the sheet surface and the nanofluid temperature. The intensity of convective heating on the sheet surface increases when the value of $\mathrm{Bi}_{1}$ increases. This leads to the growth of convective heat transfer from the hot fluid on the lower surface of the sheet to the nanofluid on the upper surface which intern enhance the thickness of thermal boundary layers. Figure 15 also demonstrates that the sheet surface and nanofluid concentration increase with an increase in $\mathrm{Bi}_{2}$, and this leads to enhance the concentration boundary layers thickness.

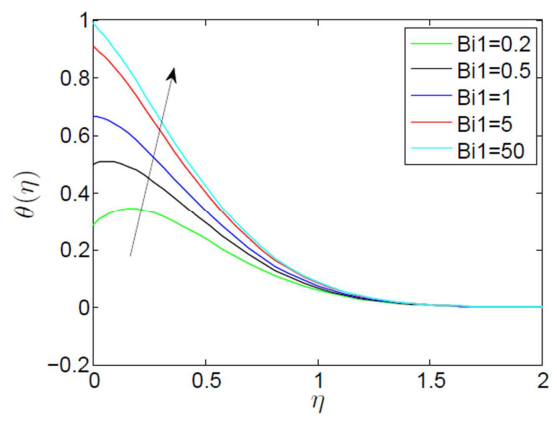

Figure 14. Temperature profiles for various values of $B i_{l}$. 


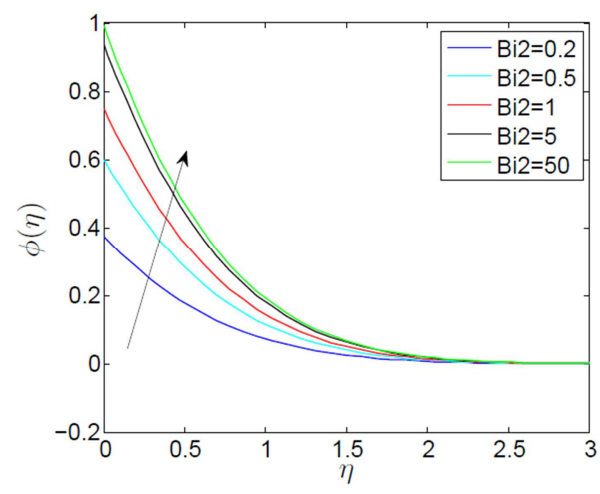

Figure 15. Concentration profiles for various values of $B i_{2}$.

\section{Conclusion}

In this study unsteady heat and mass transfer boundary layer flow of $\mathrm{Cu}-\mathrm{H}_{2} \mathrm{O}$ nanofluid past a moving wedge is considered. It is assumed that the added particles are of spherical shape, low volume percent, the suspension is at ambient conditions, and the nanoparticle volume fraction can be actively controlled at the boundary surface. The governing equations are numerically solved using SQRM. From the obtained results it can be concluded that the velocity boundary layer thickness reduces with an increase in nanoparticle volume fraction, unsteadiness, and pressure gradient parameters. The thermal boundary layer thickness increases with an increase in nanoparticle volume fraction, Eckert number, and thermal Biot number. Greater the value of unsteadiness, pressure gradient, chemical reaction and moving wedge parameters, and Schmidt number reduce the nanofluid concentration profiles.

Moreover, the skin-friction coefficient at the surface enhances with an increase in nanoparticle volume fraction, unsteadiness, and pressure gradient parameters. The local heat transfer coefficient is a decreasing function of nanoparticle volume fraction, Prandtl number, and Eckert number while it is an increasing function of unsteadiness and pressure gradient parameters. Local mass transfer coefficient is increased by increasing the value of nanoparticle volume fraction, unsteadiness, pressure gradient and chemical reaction parameters, and Schmidt number. In general, the obtained results have important practical implication in engineering and industrial processes.

\section{References}

[1] S. U. S Choi, and J. A Eastman (1995), Enhancing thermal conductivity of fluids with nanoparticles in developments and Applications of NonNewtonian Flows. ASME., 66, 99-105.

[2] T. Salahuddin, A. Hussain, M. Y Malik, M. Awais, and M. Khan (2017), Carreau nanofluid impinging over a stretching cylinder with generalized slip effects using finite difference scheme. Results in Phy., 7, 3090-3099.

[3] A. Nageeb, H. Haroun, S. Mondal, and P. Sibanda (2017), Effects of thermal radiation on mixed convection in a MHD nanofluid flow over a stretching sheet. In. J. Math. Com., Phy. Ele. Comp. Eng, 11 (2).
[4] M. S Alama, M. Ali, M. A Alim, M. J Munshi, and M. Z Chowdhur (2017), Solution of Falkner- Skan unsteady MHD boundary layer flow and heat transfer past a moving porous wedge in a nanofluid. Sci. Dir., Pro. Eng., 194, 414-420.

[5] B. K Ramesh, R. K Shreenivas, L. N Achala, and N. M Bujurk (2017), Similarity solutions of the MHD boundary layer flow past a constant wedge within porous media. Math. Prob. in Eng., doi: 10.1155/2017/1428137.

[6] V. Nagendramma, K. Sreelakshmi, and G. Sarojamma (2017), Magnetohydrodynamic heat and mass transfer flow over a stretching wedge with convective boundary condition and thermophoresis. Sci. Dir., Pro. Eng., 127, 963 - 969.

[7] W. Ibrahim, and A. Tulu (2019), Magnetohydrodynamic boundary layer flow past a wedge with heat transfer and viscous effects of nanofluid embedded in porous media, Math. Prob. in Eng., doi: 10.1155/2019/4507852.

[8] D. Srinivasacharya, U. Mendu, and K. Venumadhav (2015), MHD boundary layer flow of a nanofluid past a wedge. Sci. Dir., Pro. Eng., 127, 1064-1070.

[9] X. Xu, and S. Chen (2017), Dual solutions of a boundary layer problem for MHD nanofluids through a permeable wedge with variable viscosity. Xu and Chen Bou. Val. Prob, 147.

[10] E. Haile, and B. Shankar (2015), Boundary-layer flow of nanofluids over a moving surface in the presence of thermal radiation, viscous dissipation and chemical reaction. J. of App. Math., 10, 952-969.

[11] A. C Yunus, and A. J Ghajar (2015), Heat and Mass Transfer, fundamentals and applications. Mcgraw-Hill education, 2 Penn Plaza, New York, 5.

[12] S. S Majety, and K. Gangadhar (2016), Viscous dissipation effects on radiative MHD boundary layer flow of nanofluid past a wedge through porous medium with chemical reaction. IOSR J. of Math. 12, 71-81.

[13] S. S Motsa (2013), A new spectral local linearization method for nonlinear boundary layer flow problems. J. of App. Math., doi: $10.1155 / 2013 / 423628$.

[14] S. S Motsa, Z. G Makukula, and S. Shateyi, (2013), Spectral local linearization approach for natural convection boundary layer flow. Math. Prob. in Eng., doi: 10.1155/2013/765013.

[15] N. Ali N, J. A Teixeira, and A. Addali (2018), A review on nanofluids: fabrication, stability, and thermophysical properties. J. of Nanomaterials, doi.org/10.1155/2018/6978130.

[16] V. M Falkner, and S. W Skan (1931), Some approximate solutions of the boundary layer equations. Philos. Mag., 12, 865-896.

[17] I. Ullah, I. Khan, and S. Shafie (2016), Hydromagnetic Falkner-Skan flow of Casson fluid past a moving wedge with heat transfer. Alexandria J. of Eng., 55, 2139-2148.

[18] G. Ashwini, and A. T Eswara (2012), MHD Falkner-Skan boundary layer flow with internal heat generation or absorption. Int. J. of Math. and Comp. Sc., 6, 556-559.

[19] T. Watanabe (1990), Thermal boundary layer over a wedge with uniform suction and injection in forced flow. Acta_Mechanica, 83, 19-26. 